patient made a most rapid and perfect recovery, and in a few weeks was busily employed on his farm in good health, and perfectly relieved from his sufferings. So much for chloro. form.

I shall now conclude by observing, that all parents are now well instructed in the knowledge that simply by vaccinating their children they thereby secure them against that most loathsome and disfiguring disorder - the small-pox. And why should not they be equally well instructed in the knowledge that if ever they themselves, or any of their children, should become affected with the common symptoms of stone in the bladder, they should apply without delay to a professional man conversant with the disorder, who would immediately remove the cause, and thus save them from long.continued misery and torture?

Dundee, 1860 .

ON A

\section{CASE OF OBSTRUCTION OF THE BOWELS FROM ADHESION TO THE UTERUS.}

BY J. H. ALDRIDGE, M.D., Southampton.

MRS. S_- aged fifty-seven years, the mother of five children. About six months before her death she had a severe attack of flooding, although her menstrual discharge had ceased years before. She was always of a costive habit, and in the month of February, 1859, symptoms of obstruction of the bowels came on, which became more and more aggravated up to the period of her death on the 10th of April following. For some weeks before her decease she had stercoraceous vomiting, the ejected matters being of a yellowish colour, watery, and having a strongly-fæcal odour. She seemed to die gradually of exhaustion.

Examination two days after death. - (The abdomen only was examined.) On opening the abdominal cavity, the intestines were seen to be smeared with a yellowish-coloured, watery, offensive matter, similar to that which she had vomited during life. This fluid must, therefore, have escaped into the peritoneal cavity through some hole in the gut. However, it cannot be said that this rupture of the bowel occurred during life, because the texture of the lower part of the small intestine was found to be so extremely soft and friable that it was rent by the slightest touch. In some parts it was gangrenous. It is, then, more than likely that the tear may have taken place after death, either by the pressure of gas developed in the bowel, or by movements of the body, or while opening the abdomen. The small intestine was seen to be very much distended, particularly the lower portion, which was of enormons diameter, nearly equal to that of a normal large intestine. The coats of the ileum in nearly its whole length were in a high state of inflammation. Near the lower end, approaching the cæcum, were many dark-coloured patches, some as large as a twoshilling piece, others smaller, where the whole thickness of the intestinal wall was perfectly gangrenous. The texture of the gut for several feet above the cæcum was so friable that on moving one coil upon another it tore at various points. In the npper part of the small intestine was found the same yellowishcoloured, watery, fæcal matter that the patient had vomited during life; lower down the contents of the bowel became more consistent; and for several feet from the lower end of the ileum the latter was enormously distended with tenacious yellowishcoloured faces, very much resembling putty. The cæcum and large intestine were nearly empty, only a few knots of hardened fæces being found in the latter. In the lower end of the ileum, therefore, the obstruction was seated. On careful examination, the latter was seen to be dragged down into the cavity of the pelvis, and to be firmly adherent to the back wall of the uterus. When the small intestines and the contents of the pelvis were removed from the body, the state of matters could be clearly seen. About six inches from the ileo-cæcal valve the ileum had become firmly adherent to the posterior wall of the uterus-rather towards the right side-and to the right ovary. The gut at the adherent point made a sharp turn towards the cæcum. Accordingly, everything requiring to pass through this part of the bowel had to travel along its canal bent almost at a right angle. The calibre of the ileum at the attached point seemed smaller than normal, but not much so. It is obvious that this sharp bend in the canal of the gut must have tended very considerably to retard the passage of the fæces through it, and, the latter having been hard and dry, as is usually the case in persons of obstinately costive habit, it can easily be understood how stoppage to the passage of the contents at this point occurred. Once commenced, such an obstruction would only becorre aggravated in the course of time by the gradual accumulation of fæces above it, and by the strong muscular efforts of the bowel to propel the contents onwards, as happened in this case, in which, during life, the violent peristaltic action of the intestines conld at times be distinctly seen. It is not unlikely that if the patient had at a sufficiently early period overcome the tendency to constipation by keeping her bowels in a rather relaxed condition, the obstruction might have been averted, or at all events delayed. On removing the uterus from the body and cutting it open, the whole of the organ was seen to be one mass of epithelial cancer (cancroid), thus accounting for the floodings which the patient had some months before death, and also, in all probability, for the adhesion of the ileum to its posterior wall, as above described. The cancroid disease having implicated and eaten into the whole thickness of the uterus, even to the serous covering of the same, peritonitis seems to have been set up at this point, and to have thus occasioned the attachment of the loop of intestine to it. The coats of the ileum for an inch or two above and below the adherent part seemed to be perfectly healthy. The adhesions between the small intestine and the uterus were very firm, and must, therefore, have existed for a considerable time, perhaps for months.

At what period the cancroid disease of the womb began it is of course impossible to say, but that it had already attacked the uterus six months before the fatal termination of the case is evident from the occurrence of severe flooding at that time. If obstruction of the bowels had rot supervened, and thus put an end to the patient's existence, it is very probable that ultimately a fistula between the uterus and ileum might have taken place by the extension of the cancroid disease througb the adbesions and through the coats of the gut.

Southampton, 1860.

REPORT OF

\section{TWO CASES OF IDIOPATHIC TETANUS TREATED BY INDIAN HEMP.}

\section{BY WILLIAM FARRAGE， L.R.C.P.E.}

ThE following cases of Idiopathic Tetanus treated by Indian Hemp, occurring during my residence in Melbourne, Australia, may be of interest at the present time, when the treatment of the disease in its traumatic form is so fully engaging the attention of the profession.

CASE 1. - Sept. 21st, 1857. - Mr. - - aged thirty-two, wool-worker on the banks of the Yarra-Yarra, a man of temperate and quiet habits, for two or three days previous to my visiting him had been suffering from stiffness of the muscles of the neck and slight rigidity of the lower jaw, which was attributed to a common cold. On the above day, before my visit, he had been seized with spasm and great pain, every few minutes, along the whole spine; by the slightest movement, touch, or noise, the muscles of the back were thrown into violent spasmodic contractions, bending the body forcibly backwards. The lower extremities were not affected. There was slight stiffness of the lower jaw, but no trismus; no difficulty in swallowing. Tongue clean; pulse 80, full, and strong; skin moist; no tenderness over the abdomen; no head symptoms bowels had acted from castor oil. The following pills were ordered: Calomel, eight grains; extract of hyoscyamus, twelve grains. Divide into four pills: two immediately, and the others at night. A purgative enema the following morning, with two drachms of spirit of foetid ammonia; and a liniment to be rubbed along the spine, composed of tincture of opium, tincture of cantharides, and camphor liniment.

22nd. - Ten A. M.: Bowels acted twice, but no abatement of the spasms. The abdominal muscles were now tense and rigid, and the patient complained of great pain. Turpentine epithem to the abdomen, followed by hot fomentations. To take the following mixture: Solution of hydrochlorate of morphia, and tincture of hyoscyamus, of each two drachms; spirit of com. pound sulphuric ether, a drachm and a half; camphor mixture, four ounces: the fourth part every two hours. 
23rd. - Twelve A. M. : No abatement of the spasms; still increasing. Strength good; pulse 84. Repeat enema, and to take the following pills: Extract of cannibis indicus, six grains; extract of byoscyamus, and assafortida, of each half a drachm : divide into twelve pills; one every hour.

24th.-Ten A.M.: Bowels had not acted; no abatement of spasms. To take tincture of Indian hemp, thirty drops in water every two hours; and repeat the enema.

25th. - Bowels acted; spasms still increasing; pulse 72, and much weaker; skin cold and persniring; tongue clean. Wine and beef-tea to be taken every two hours, and the Indian hemp continued. Counter-irritation to the spine with croton oil and turpentine.-Five P.M.: Much improved; pulse 84, and stronger.

26th. - Nine A. M. : Spasms still continne, but more confined to the centre of the spine; pulse 80 , firm and strnng; each paroxysm to-day is nshered in with a cry of pain referred to the centre of the back; expression of face bad- " that peculiar expression noticed in tetanus." Continue the Indian hemp, increased to forty minims; and beef-tea and wine.-Five P. M.: Much worse. The muscles of the whole system were now more or less involved with spasm, and trismus was now complete. While I was standing by the bed-side, he was seized with a severe fit, the respiratory muscles being affected to such a degree as to prevent him from breathing; the jaw fixed and rigid, the eyes fixed, and the face fearfully distorted; respiration was suspended, the heart ceased to pulsate, and he was apparently suffocated. In a few minutes there was relaxation of the muscles, but no return of the heart's action or respiration: he was to all appearance dead. Something must be done to try to bring about reanimation. I put in operation Marshall Hall's method of treatment. In about five minutes there was a deep inspiration, followed soon after by pulsation of the heart. The treatment was continued for some time, until he was quite restored. There was no return of spasm with the reanimation. Continue the Indian hemp, beef-tea, and wine; and the follow. ing draught to be taken immediately : solntion of hydrochlorate of morphia, forty-five drops; tincture of hyoscyamus, forty-five drops ; camphor mixture, one ounce and a half. - Fight P.M. Much better, having slept for several hours; slight return of spasms in the back on awaking.

27th.-Ten A.M.: Had spent a good night; slept well; pulse 84, full and strong; expression of face natural ; makes no complaint of pain; no return of trismus; no difficulty in swallowing.-Three F.M.: Still improving. Continue the Indian hemp, beef-tea, and wine. As the bowels had not acted, he was ordered to take the following draught immediatelyfive grains of calomel, and half a grain of hydrochlorate of morphia; also a purgative enema in the morning.

28th. -Ten A.M.: Bowels acted twice; much improved; pulse 76, full and strong; tongue clean; still slight spasmodic twitches in the muscles of the spine about every hour, but no pain.

29th.-Eleven A.M.: Still improving; pulse 84, full and strong; tongue clean; no tenderness on pressure over the abdomen or spine; spasms of back continue, though slight. About seven P.M. I received a message to visit hiw, as he had been very restless during the afternoon. "His residence being about two miles' distance, and not an urgent message to visit him immediately," I arrived there in the course of an hour, and found him quite dead. In attempting to get out of bed, he was seized with spasm of the entire body, involving the respiratory muscles, and died in less than two minutes. He was conversing with his wife freely about five minutes before this sudden return of spasm, and said that he felt much better and quite free from pain. There was no chance of reanimation, as he had been dead nearly an hour. No post-mortem examination of the body was made.

There was no prostration of nervous power to cause death. The most prominent symptoms had subsided-namely, muscular rigidity and spasm. The pulse was good, all expression of suffering gone, and sleep restored. Spasm of the respiratory muscles and heart could be the only cause of this sudden death.

CASE 2.-In 1857, I was requested to visit the son of a medical man, aged twelve years. He had been complaining of stiffness of the muscles of the neck and lower jaw for,two or three days, attributed to a common cold, arising from being overheated when playing at cricket, and afterwards sitting on the wet grass. When I saw him, the spasm had extended to the muscles of the back, abdomen, and extremities, with great pain in the contracted muscles; pulse and respiration quick, with complete trismus. This latter symptom continued for six or seven days, without any relaxation of the muscles of the lower jaw.

The treatment was the same as in the former case: tincture of Indian bemp, ten minims every two hours, increased to twenty minims; calomel occasionally at night, and enema on the following morning; beef-tea and wine, with connter-irritants to the spine. The spasm and rigidity of the muscles were so great in this case, that when the little fellow was raised up he was as rigid as a block of woot. All his medicine and ourishment were sucked through an opening between the teeth with a small tube. The spasms partially abated after the seventh ray, and he quite recovered. The only arlditional treatment was during the convalescence, a little citrate of iron and quinine.

Melbourne House, Hampstead, Arg. 1860.

\section{A}

OF THE PRACTICE OF

\section{MEDTCINE AND SURGERY IN THE}

HOSPITALS OF LONDON.

Nulla est alia pro certo noscendi via, nisi quam plurimas et morborum et dissectionum historias, tam aliorum proprias, collectas habere et inter se com. parare.-HorgagNI. De Sed. et Caus. Horb., lib. I4. Procmium.

\section{ST. GEORGE'S HOSPITAL.}

\section{VACCINATION, FOLLOWED BY INFLAMMATION AND ABSCESS} OF THE ARM ON THE RECEIPT OF A BLOW UPUN THE SCAB ; FATAL PY

(Under the care of Mr. CASSAR HAwKINS.)

TнЕ phenomena detailed in the following case are of such an unusual character that we feel disposed to set them down as the result of some inherent vice in the constitution of the patient. A rather severe blow received upon the dried-up vesicle of vaccination was followed by extensive inflammation and abscess, of so serions a nature as to end in pyæmia and death. It is, of course, a common occurrence for an accidental blow or injury to be received on the vaccine vesicle of a child, and to be followed, perhaps, by a certain amount of inflammation; but seldom indeed has the mischief proceeded so far as in the present instance. We have also known sloughing to ensue around the vesicle, without preceding injury to the part. Dr. Gregory mentions, in his "Practice of Medicine," that in some instances the specific inflammation or areola is very violent, extends from the shoulder to the elbow, invades the trunk of the body, and requires to be assuaged by cold lotions; but this, we may observe, is one of the irregularities in the phenomena of vaccination. We place the present case on record, however, from its extreme rarity in respect of the severity of the symptoms which supervened. A point of interest in the post mortem examination was the detection of air in the pericardium.

Charlotte W-_, aged thirty five, admitted March 31st. One month previously she was vaccinated; the vaccine took well, but when the pustule had scabbed over she gave her arm a violent blow; this was followed by inflammation of the arm. On admission, the upper part of the left arm was very red, swollen, and painful, and there was threatened suppuration at the upper and back part. She looked pale and thin, and was given meat and porter. The swelling at the back of the arm increased, and on the $9 \mathrm{~h}$ of April Mr. Hawkins opened an abscess in that situation. It appeared to extend across the back part of the shoulder joint and under the pectoral muscles. A large amount of thick pus escaped.

April 14th. -She had a rigor which lasted half an hour. Complained of much pain in her arm; the abscess was discharging freely. Tongue loaded; pulse 84, weak. She was given au ounce of brandy and a saline mixture with ipecacuan (five grains) every six hours.

15th. -The countenance was anxious; she was constantly 263 